\title{
Environmental and economic analysis of the Turin incineration plant
}

\author{
D. Panepinto, A. Senor \& G. Genon \\ Polytechnic University of Turin, Italy
}

\begin{abstract}
There has been a great deal of attention given to the necessity to improve innovative systems of energy recovery and this, together with a positive trend in the increase of waste, has lead to a need to consider systems of the disposal and treatment of waste that enable the reduction of both volumes and energy and, if possible, a recovery of materials. Incineration is a system that offers both of the aforementioned opportunities (volume reduction and energy recovery).

The aim of this work is to analyze the waste incineration plant that is built in Turin (Piedmont, North Italy). We analyze two different kinds of energy recovery: from one side, a recovery only of electric energy (electrical configuration) and on the other side, a recovery both of electric and thermal energy (cogenerative configuration) with different hypotheses on their connections to the district heating network from an environmental and economic point of view. From an environmental point of view the aim is to understand which of the two energy recovery configurations is more convenient (in terms of environmental compatibility) and from an economic point of view the aim is to understand if the environmental convenience corresponds to the economic convenience.

Keywords: incineration, energy recovery, electric energy, thermal energy, environmental compatibility, externality, dispersion models, district heating system.
\end{abstract}

\section{Introduction}

Given the interest in the production of thermal and thermo-electric energy from non-fossil fuel sources, the valorization of potential energy contained in the downstream waste flow is an important consideration [1-6]. 
The Turin plant is certainly an interesting example, as it is under construction as an incinerator for the treatment of municipal solid waste residuals from separated collections. The evaluation may be considered to have a dual purpose: specifically, to establish the compatibility of the two different configurations at the Turin plant, and in general, as a useful decision-making tool for policy-makers.

\section{Materials and methods}

\subsection{Incineration plant: description}

The incineration plant in this study is authorized to treat $421,000 \mathrm{t} / \mathrm{y}$ of municipal solid wastes that are collected after removal of reusable materials; this residual fraction has a lower heat value of $11 \mathrm{MJ} / \mathrm{kg}$. The plant will operate for $7,800 \mathrm{~h} / \mathrm{y}$ and it will consist of three equal lines; each line will consist of a combustion zone consisting of a moving grate system, an energy recovery section operating with a boiler and a steam turbine, and a flue gas treatment apparatus consisting of an electro filter for dust removal, a dry scrubber (with injection of sodium bicarbonate and activated carbon) for the removal of acid gases as well as organic and inorganic micro pollutants, a bag filter for the removal of the residual and generated dust, and a final selective catalytic removal system for the reduction of $\mathrm{NO}_{\mathrm{x}}$. With this flue gas treatment line it is possible to obtain pollutant concentrations in the output flue gas lower than the maximum permitted by national law (D. Lgs. 133/2005). Table 1 displays the incineration plant emissions produced while functioning with either three or two lines (in this second case one line would be in maintenance).

Since all the carbons present in the waste input are oxidized into carbon dioxide during combustion, the emission will be 312,711.89 t/y for the hours that the plant operates with three lines, and 49,536.66 t/y for the hours that the plant operates with two lines (total emission equal of $362,248.55 \mathrm{t} / \mathrm{y}$ ).

Table 1: Incineration plant emissions.

\begin{tabular}{|l|c|c|c|c|c|}
\hline \multicolumn{7}{|c|}{ Normal operation with 3 lines* Authorized value normalized at 11\% of O2 } \\
\hline & $Q_{\text {flu gas }}\left[\mathrm{Nm}^{3} / \mathrm{h}\right]$ & $\begin{array}{c}\mathrm{C}_{\text {flu gas }} \\
{\left[\mathrm{mg} / \mathrm{Nm}^{3}\right]}\end{array}$ & $\begin{array}{c}\text { Pollutant load } \\
{[\mathrm{t} / \mathrm{h}]}\end{array}$ & $\mathrm{t}[\mathrm{h} / \mathrm{y}]$ & $\begin{array}{c}\text { Pollutant load } \\
{[\mathrm{t} / \mathrm{y}]}\end{array}$ \\
\hline $\mathrm{NO}_{\mathrm{x}}$ & $237,795.61$ & $87.50^{*}$ & 0.021 & 7,272 & 151.31 \\
\hline $\mathrm{SO}_{2}$ & $237,795.61$ & $12.50^{*}$ & 0,003 & 7,272 & 21.62 \\
\hline $\mathrm{PM}_{10}$ & $237,795.61$ & $6.25^{*}$ & 0.001 & 7,272 & 10.81 \\
\hline \multicolumn{7}{|c|}{ Maintenance operation at 2 lines * Authorized value normalized at 11\% of O2 } \\
\hline \multicolumn{7}{|c|}{$\begin{array}{l}\mathrm{Q}_{\text {flu gas }} \\
{\left[\mathrm{Nm}^{3} / \mathrm{h}\right]}\end{array}$} & $\begin{array}{c}\mathrm{C}_{\text {flu gas }} \\
{\left[\mathrm{mg} / \mathrm{Nm}^{3}\right]}\end{array}$ & $\begin{array}{c}\text { Pollutant load } \\
{[\mathrm{t} / \mathrm{h}]}\end{array}$ & $\mathrm{t}[\mathrm{h} / \mathrm{y}]$ & $\begin{array}{c}\text { Pollutant load } \\
{[\mathrm{t} / \mathrm{y}]}\end{array}$ \\
\hline $\mathrm{NO}_{\mathrm{x}}$ & $207,522.93$ & 87.50 & 0.018 & 1,320 & 23.97 \\
\hline $\mathrm{SO}_{2}$ & $207,522.93$ & 12.50 & 0.003 & 1,320 & 3.42 \\
\hline $\mathrm{PM}_{10}$ & $207,522.93$ & 6.25 & 0.001 & 1,320 & 1.71 \\
\hline
\end{tabular}




\subsection{Incineration plant: operating conditions}

The first step was to define the hypothesis for plant operation (Table 2): since summer is the lowest season for the plant's energy recovery operations, the general stoppage of one week will be required for maintenance in July.

The second step was to determine the amount of thermal power that can be exported as a function of the produced electric power that can be introduced into the national network considering four situations: electric production alone; CHP with $33 \%$ recovered thermal power $\left(35 \mathrm{MW}_{\text {th }}\right.$ ); CHP with $66 \%$ recovered thermal power $\left(70 \mathrm{MW}_{\text {th }}\right)$; $\mathrm{CHP}$ with $100 \%$ recovered thermal power $\left(106^{\circ} \mathrm{MW}_{\text {th }}\right)$.

Table 2: Hypothesis of plant functioning.

\begin{tabular}{|l|c|}
\hline \multicolumn{1}{|c|}{ Management } & Plant functioning $(\mathrm{d} / \mathrm{y})$ \\
\hline 3 lines & 303 \\
\hline 2 lines & 55 \\
\hline Plant total stop & 7 \\
\hline
\end{tabular}

\subsection{Different hypothesis for connection to district heating network}

With the technical support of CSI-Piedmont, a spatial and urban analysis was performed by accurately identifying the number of dwellings potentially connectable, depending on the intended use and size of dwelling (cubic meters), to the district heating network. We defined three different hypotheses of connection to the DH network (in agreement with the document "Piano di sviluppo del teleriscaldamento nell'ambito di Torino - PSLRTO" [9]) that, combined with different CHP plant operations, allows for the results in Table 3.

If we analyze the results that are reported in Table 3 it can be seen that the differences between Hypothesis $2 a$ and $2 b$ and between Hypothesis $3 a$ and $3 b$ are attributable to an estimation of the thermal energy produced in the summer months and exported to a district cooling user network.

Table 3: Hypothesis of connection to the district heating network.

\begin{tabular}{|c|c|c|c|c|}
\hline $\begin{array}{l}\text { Connection } \\
\text { hypothesis }\end{array}$ & $\begin{array}{c}\text { Common } \\
\text { connectable to } \\
\text { DH }\end{array}$ & $\begin{array}{c}\text { Served } \\
\text { volume } \\
\left(\mathrm{Mln} \mathrm{m}^{3}\right)\end{array}$ & $\begin{array}{l}\text { CHP Plant } \\
\text { operation }\end{array}$ & $\begin{array}{l}\text { Supplied thermal } \\
\text { energy }\left(\mathrm{MWh}_{\mathrm{th}}\right)\end{array}$ \\
\hline Hp. 1 & Beinasco & 0.53 & 9 months & $24,138.00$ \\
\hline Hp. 2a & \multirow{2}{*}{$\begin{array}{c}\text { Beinasco } \\
\text { Collegno } \\
\text { Grugliasco } \\
\end{array}$} & 6.82 & 9 months & 310,160 \\
\hline Hp. 2b & & 6.82 & All year & 318,190 \\
\hline Нp. 3a & \multirow{2}{*}{$\begin{array}{c}\text { Beinasco } \\
\text { Collegno } \\
\text { Grugliasco } \\
\text { Torino }\end{array}$} & $15.30^{*}$ & 9 months & 626,195 \\
\hline Hp. 3b & & $15.30^{*}$ & All year & 714,905 \\
\hline
\end{tabular}




\subsection{Trend for exported energy considering requirements}

We defined the hypotheses of plant operation for different scenarios of energy recovery, shown in Figures 1, by taking into account the number of dwellings connectable to the $\mathrm{DH}$ network, the hypotheses of plant operation, the ratio of thermal power to electric power and the thermal requirements of the potential users (considering the average trend over the last 10 years), with respect to the cumulate curve of thermal load for the Turin province.

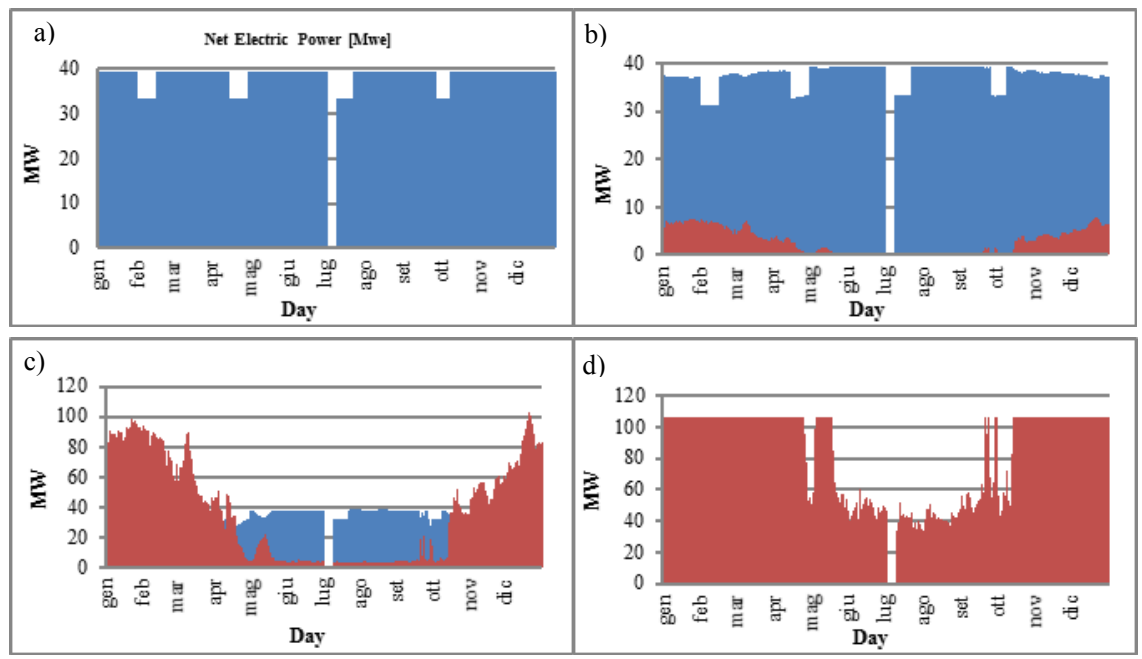

Figure 1: Operation hypothesis: a) electric configuration, b) CHP hp 1, c) CHP hp 2b, d) CHP hp 3 b.

Graph a) in Figure 1 reports the net electric power that can be introduced into the electrical network after the power consumed by the plant has been subtracted in case of only electric configuration; when analyzing the results reported in graphs b), c) and d) it can be seen that the hypothesis of CHP configuration is included only for the entire year.

\section{Methodology for evaluation of air environmental impact}

Since the evaluation of environmental compatibility is considered chiefly with respect to the effects of the plant operation on the air quality, the analysis was performed using two different tools: an environmental balance, in order to define the real introduced and avoided emission fluxes; an implementation of the pollutant dispersion model, to evaluate the real air quality modification consequent to the incineration plant start-up, and the phasing-out of the substituted energy sources. 


\subsection{Energy and environmental balance}

In order to evaluate the introduced load and the local and global environmental benefits of substitution, it is necessary to compare the emissive fluxes before and after the start-up of the incinerator. The emission factors (concerning the production of thermal and electric energy) used to define the emission avoided are shown in Table $4[7,10]$.

From the urban analysis we obtained the information that the average composition of the domestic boiler in the analyzed area is 95\% methane and 5\% fuel oil.

The formulation of the environmental balance on the local scale is only preparatory for the implementation of the pollutant dispersion model. The aim of the formulation of the environmental balance on the global scale, though, is to perform a comparison between the different scenarios concerning the emission of carbon dioxide.

Table 4: Emission factors for the production of thermal and electric energy.

\begin{tabular}{|l|c|c|c|}
\hline & \multicolumn{2}{|c|}{ EF for thermal energy production (g/GJ) } & $\begin{array}{c}\text { EF for electric energy } \\
\text { production }(\mathrm{mg} / \mathrm{kWh})\end{array}$ \\
\hline & Methane & Combustible oil & 600 \\
\hline $\mathrm{SO}_{2}$ & 0.83 & 76.38 & 943 \\
\hline $\mathrm{NO}_{\mathrm{x}}$ & 42.06 & 56.23 & 29 \\
\hline $\mathrm{PM}_{10}$ & 6.70 & 5.48 & 675,000 \\
\hline $\mathrm{CO}_{2}$ & $55,500^{*}$ \\
\hline
\end{tabular}

\subsection{Implementation of pollutant dispersion models}

In order to evaluate the severity of the local environmental impact produced by the plant, it is necessary to consider the results of the dispersion models. With this approach it is possible to calculate the real air-quality modifications: the concentrations (annual mean values and maximum hourly values) that will be created by the future plant, and the elimination of concentrations corresponding to the sources that will be avoided (from the elimination of existing domestic boilers). This comparison was performed by constructing concentration maps.

The maps were constructed from the results of the simulation of the atmospheric dispersion of pollutants emitted from all relevant sources, using the Aermod model. It is a Gaussian model, which uses the Gauss function of errors as an analytical solution of the equation of transport in the atmosphere, shown below (US Environmental Protection Agency).

\subsection{The external costs (social)}

The assessment of the externalities was developed by analysing the rigorous methodology "ExternE" based on a bottom-up approach (Impact-PathwayApproach), which allows to estimate the environmental benefits and costs, 
following the path from the source of emissions to get the changes that they cause to the quality of air, soil and water.

A simplified method was carried out based on the distribution of log-normal confidence intervals entitled "method UWM = uniform world model", which shows a summary of the role of the most important parameters of the impact analysis.

Table 5 shows data that is useful to the economic assessment of external costs for various pollutants with reference to Urban Area and Stack Height $h_{s}=100 \mathrm{~m}$.

Operatively, the simplified methodology is translated into following equation:

$$
\text { Costs }(€ / y)=\text { Externality }(€ / \mathrm{t}) * \text { Emissions }(\mathrm{t} / \mathrm{y})
$$

Furthermore, it has been necessary to place well-defined limits for the choice of the analysis detail: the monetary valuations of externalities affecting the downstream process of the thermal cycle of the incinerator without taking care of what happen upstream from the incineration process. We have balanced the negative externalities arising from the emissions of the incinerator, with positive externalities due, on the one hand, the replacement of boilers for heating with district heating service (local scale) and on the other hand, the replacement of heating boilers and district heating service and to thermal power stations of the country (global scale).We have not taken into account the externalities arising from waste management: the alternative to incineration should have been laying waste to landfill. Having avoided this kind of disposal, which is little integrated, this is the last choice in waste management as it incurs additional externalities.

Table 5: Externality [6].

\begin{tabular}{|l|l|l|}
\hline & {$[€ / \mathrm{Kg}]$} & {$[€ / \mathrm{t}]$} \\
\hline Dusts & 12 & $12.000,00$ \\
\hline $\mathrm{NO}_{2}$ & 3,4 & $3.400,00$ \\
\hline $\mathrm{SO}_{2}$ & 3,5 & $3.500,00$ \\
\hline $\mathrm{CO}_{2}$ & 0,019 & 19,00 \\
\hline
\end{tabular}

\subsection{The financial plan of industrial analysis of the plant}

The financial plan qualifies firstly, as an instrument of economic evaluation, by comparing the costs and expected revenues from the project, and, secondly, as an element of financial evaluation, with regarding the project's ability to serve its debt.

The point of view adopted by the analysis of the business plan is a single actor (private - TRM). Wanting to model an Economic-Financial Plan, we start from the idea that the final operation can be considered in two time periods:

- Construction and provisional operation, from 01/01/2010 to 31/12/2013;

- Business operation, from 01/01/2014 to 31/12/2033.

Looking at these time periods, the costs represent the value of resources to be used in each period, regardless of the date planned for their payment, i.e. material, services, disposal, electricity transmission, gas consumption, the 
contributions of local authorities, staff, ordinary maintenance and scheduled maintenance. The revenues are the total amount of expected sales of each year, regardless of the date scheduled for their collection i.e. disposal of waste, contributions and local governments, electricity and green certificates. However, for CHP scenarios we have also taken into account revenue from thermal energy.

\section{Results and discussion}

The first tool we used in evaluating environmental compatibility was the environmental balance. In consideration of the quality of the emissions, on both the local and global scales, the analyzed pollutant parameters were: dust, $\mathrm{SO}_{\mathrm{x}} \mathrm{e} \mathrm{NO}_{\mathrm{x}}$ on the local scale, and $\mathrm{CO}_{2}$ on the global scale.

\subsection{Results of environmental balance}

For the evaluation of the global scale environmental balance, the obtained results are summarized in Figure 2.

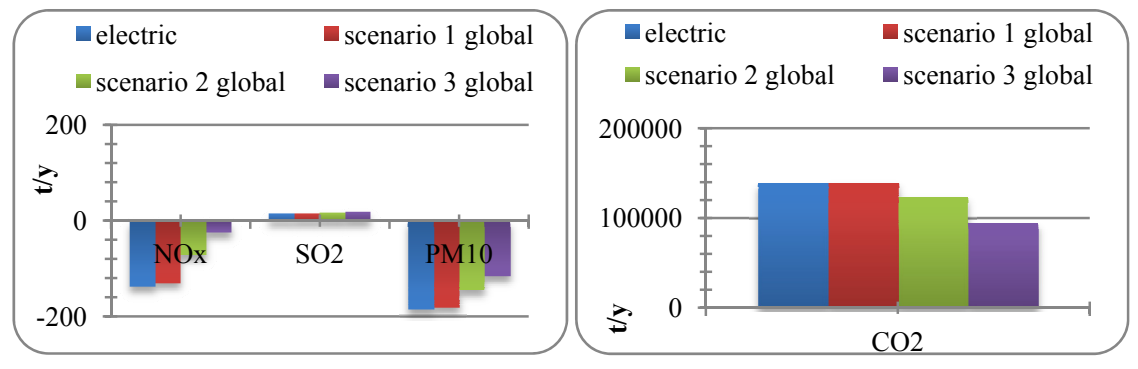

Figure 2: $\quad$ Results of global scale environmental balance.

From Figure 2 it can be seen that, after the start-up of the plant, the total emissive flux of the pollutant parameters $\mathrm{NO}_{\mathrm{x}}$ and dust will decrease; the reason of this decrease arises from a better emission factor for these parameters in the case of the MSW incineration plant in comparison with the performances of the national electric energy conventional producers; the cogenerative scheme presents a negative aspect from this point of view, chiefly for the high percentage of utilization of the district heating connection.

In every considered scenario an increase of $\mathrm{CO}_{2}$ emissions can be observed as a consequence of the activation of the plant: increasing the district heating network, the $\mathrm{CO}_{2}$ emission decreases, from 140,000 t/y for cogenerative Scenario 1 to a value of $92,000 \mathrm{t} / \mathrm{y}$ for the scenario of maximum connection to the heating network.

The reason for this emission saving must be sought, firstly in the value of emission factors $\mathrm{EF}\left(\mathrm{kg} \mathrm{CO}_{2} / \mathrm{GWh} ; \mathrm{EF}_{\mathrm{e}}=199,800-\mathrm{EF}_{\text {th }}=675,000\right)$ as can be seen from Table 4; secondly, for the non-linear thermal and electrical energy produced. 
Concerning the $\mathrm{CO}_{2}$ balance, another aspect that we must considerer is the $\mathrm{CO}_{2}$ avoided by elimination of emission in landfill: taking into account the stoichiometric of conversion [7] it can be established that for $100 \mathrm{~g}$ of waste there is the generation of $29.78 \mathrm{~g}$ of $\mathrm{CH}_{4}$ and $58.91 \mathrm{~g}$ of $\mathrm{CO}_{2}$.

On the local scale, environmental balance has been used for an evaluation of the real modification of the air quality, by using atmospheric dispersion models to establish the ground-level pollutant concentrations. The results of the local scale balance are presented in Figure 3.

The local-scale results indicate that the activation of the plant will lead, in every case, to an increase in the emissive flux for all parameters; this effect can be at least partially diminished by the adoption of the cogenerative scheme.

By analyzing Figure 3 we can see that in terms of environmental compatibility the best hypothesis is the Hypothesis 3, because in this hypothesis we assume that all the thermal energy produced by the incineration plant is transferred by the DH network to the domestic user.

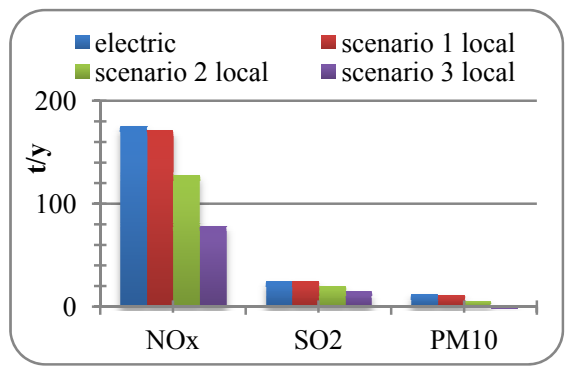

Figure 3: Local scale balance results.

\subsection{Results of the application of the dispersion model}

To define the dispersion and transport of pollutants, the Aermod model, which was developed for the EPA (Environmental Protection Agency) by the American Meteorological Society (AMS) as an evolution of the well consolidated Gaussian model ISC3, was used.

An analysis was performed of the parameter $\mathrm{NO}_{\mathrm{x}}$ by considering the low importance of the parameter $\mathrm{SO}_{\mathrm{x}}$ and assuming the same behaviour as for the parameter PM (proportionality) by disregarding the chemical transformation and removal phenomena.

In order to establish the ground level concentration within an area extended to $40 \mathrm{x} 40 \mathrm{~km}$, the methodology that was utilized is as follows: Firstly, a set of maps were constructed of ground-level concentrations consequent upon the activation of the incineration plant; secondly, barycentre stacks were posited for each zone of the district heating utilization (home boilers); finally, the result was obtained by calculating the difference between the two results, i.e. the added emissions minus the avoided emissions (substituted thermal plants). 
With this data set, we considered the general yearly trend for all the $\mathrm{DH}$ connection scenarios, and the more critical days for the maximum concentrations with regard to the larger connection hypothesis (scenarios $2 b$ and $3 b$ ).

The results are as follows, taking into account that three emissive situations have been considered:

a) emissions from the incineration plant alone;

b) incineration emissions minus the contribution of eliminated thermal plants in the hypothesis $2 \mathrm{~b}\left(6.82 \mathrm{Mm}^{3}\right.$ connected);

c) incineration emissions minus the contribution of eliminated thermal plants in the hypothesis $3 \mathrm{~b}\left(15.3 \mathrm{Mm}^{3}\right.$ connected).

First we considered the mean annual ground-level concentration values and the maximum concentrations deriving from the incineration plant and from the thermal plants, in the two scenarios. The values were as follows:

- incineration: $1.7 \mu \mathrm{g} / \mathrm{Nm}^{3}$;

- hypothesis $2 \mathrm{~b}: 0.084 \mu \mathrm{g} / \mathrm{Nm}^{3}$;

- hypothesis 3b: $0.09 \mu \mathrm{g} / \mathrm{Nm}^{3}$.

Comparing the territorial distribution of the annual mean ground level concentrations it may be observed that, in the case of the substitution, there is a very small advantage for the zones of maximum impact, meaning that the very limited criticality on the more exposed zone remains. In any case, because of the maximum value allowed by National law is $40 \mu \mathrm{g} / \mathrm{Nm}^{3}$ (D. Lgs. 152/2006), increasing by just $1 \mu \mathrm{g} / \mathrm{Nm}^{3}$ following activation of the plant, the real plant impact is minimal.

The situations that can be observed in the more critical days of the year, the maximum values corresponding to the emissions of the incineration plant and of the substituted thermal plants are as follows:

- incineration : $\quad 3.15 \mu \mathrm{g} / \mathrm{Nm}^{3}$ (corresponds to $1 / 12$ );

- hypothesis $2 \mathrm{~b}$ : $38 \mu \mathrm{g} / \mathrm{Nm}^{3}$ (corresponds to $1 / 12$ );

- hypothesis $3 \mathrm{~b}$ : $40 \mu \mathrm{g} / \mathrm{Nm}^{3}$ (corresponds to $8 / 1$ ).

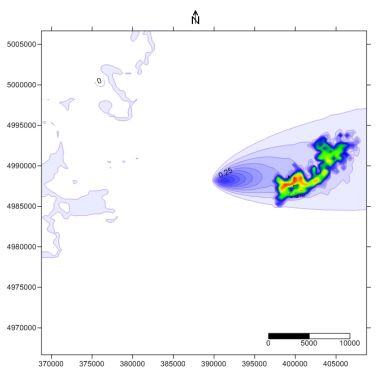

$\left[\mu \mathrm{g} / \mathrm{m}^{3}\right]$

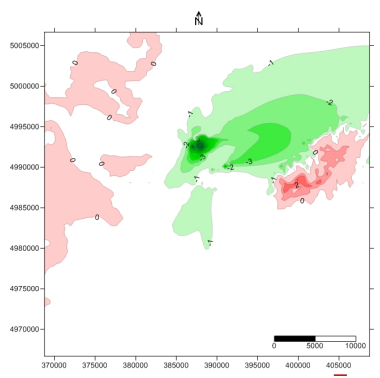

$\left[\mu \mathrm{g} / \mathrm{m}^{3}\right]$

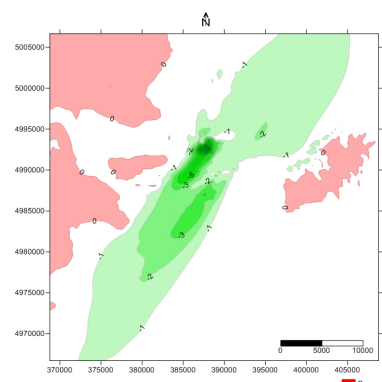

$\left[\mu \mathrm{g} / \mathrm{m}^{3}\right]$
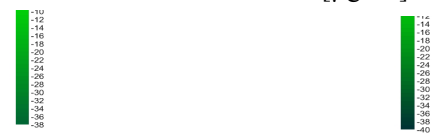

Figure 4: Left - local maximum effect of the plant (1/12). Center - Balance effect Hp. 2b (1/12). Right - Balance effect Hp. 3b (8/1). 
By evaluating the reported results, it can be observed that on the first hand there is a slight worsening $\left(2 \mu \mathrm{g} / \mathrm{Nm}^{3}\right)$ in the air quality in some more elevated zones, but these zones are in areas with quite low population density, and where the background pollutant concentration is in general very limited; in contrast, for the days of maximum effect of pollution emission and higher district heating utilization there is a very important advantage in terms of eliminated pollution, both in the areas where the district heating is used and also in the surrounding areas not yet concerned about atmospheric pollutant transport; this effect can lead to a decrease of daily mean concentration of more than $40 \mu \mathrm{g} / \mathrm{Nm}^{3}$, and from an initial estimation, could affect a population of 150,000 inhabitants.

\subsection{Results of the externality assessment}

Overall, adding the economic contribution of each pollutant, on local scale, there is a negative economic burden for all scenarios considered, although there is a reduction of four times, passing from 1 to 3 CHP scenario.

Moving on to analyse the global externalities, carbon dioxide gives a huge contribution to the budget statement. For both assets, cogenerative and electric, the monetary value is mostly resulting from the balance between $\mathrm{CO}_{2}$ and $\mathrm{PM}_{10}$ while sulphur oxides and nitrogen play only a secondary role.

With the financial statements of the externalities discounted and correlated to the whole life cycle of the WTE plant, it emerges that only the wider use of cogeneration ( $3 \mathrm{a}$ and $3 \mathrm{~b}$ CHP scenario) manages to obtain social benefits i.e. positive externalities.

\subsection{The results of the financial plan of the project}

Taking into account the "financial plan of the project", the society TRM or the operator of the plant is able to obtain in each analysed scenario, a Net Actual Value of Economic Plan (NPV) positive ( $>0$ ), but the highest financial gains are found for the electric configuration. The reason for this must be sought in the low valorisation of thermal energy sold in the form of heat through district heating in the cogenerates case (CHP).

Sensitivity analysis of revenues by the thermal energy injected into the network was also carried out to check what it should be, for each co-generative scenario, using the unit monetary value ( $€ /$ GWht) of the heat injected into the network so that the NPV of cogeneration is equal to the NPV of electric configuration.

The results show that it is possible to equate the NPV of the financial plan for the electric configuration, with just $55.000 € / \mathrm{GW}_{\mathrm{ht}}$ for the 1 CHP scenario, falling down to nearest $35.000 € / \mathrm{GW}_{\mathrm{ht}}$ for the CHP $2 \mathrm{~b}$ scenario and up to $40.000 € / \mathrm{GW}_{\mathrm{ht}}$ for the CHP $3 \mathrm{~b}$ scenario. The assumed percentage reductions of revenues for the district heating service for each CHP scenario are proportional to the implementation of the thermal dispatching network: Hp. $1=5 \%$, Hp. $2 b=17 \%$, Hp. $3 b=43 \%$. 


\section{Conclusions}

The results obtained for energy recovery from the waste incineration, in both the electricity and cogenerative configurations, underscore the high energy efficiency of the combined production of heat and electricity (CHP), and the opportunity to minimize the environmental impact by including cogeneration in a district heating scheme.

To conclude our analysis, the following points may be considered:

- It has been possible to establish the environmental compatibility of the plant by evaluating the possibility of obtaining concentration values significantly lower than allowed limits;

- The emissive environmental balance leads to definitive information only for $\mathrm{CO}_{2}$;

- The ground-level concentration maps establish a fundamental baseline for the local analysis: the mean annual values, for connection to the three nearest municipalities (Beinasco, Collegno, and Grugliasco) and also extending to Torino, it is possible to achieve minimal ground-level concentration increases (roughly $1 \mu \mathrm{g} / \mathrm{m}^{3}$ ) of $\mathrm{NO}_{\mathrm{x}}$, over current levels. This worsening is due to the limited possibility of using the thermal power in the summer, where the incineration emissions are continuous and constant; another consideration is the strong effect of stack height on emissions. On the contrary, if we consider the most advantageous periods in consequence of the district heating, it is possible to observe important improvements for the ground-level $\mathrm{NO}_{\mathrm{x}}$ concentrations (recovery from values as high as $42 \mu \mathrm{g} / \mathrm{m}^{3}$ );

- A disregarded, but very important aspect in the evaluation of the balance for the $\mathrm{CO}_{2}$ parameter is that the main purpose of the incinerator is final waste disposal (with energy recovery); an alternative solution (the landfill, by necessity) should lead to important emissive fluxes of $\mathrm{CO}_{2}$ which should be considered in a complete assessment;

- The society TRM or the operator of the plant, is able to obtain, in each analysed scenario, a Net Actual Value of Economic Plan positive $(>0)$ but the highest financial gains are found for the electric configuration, the reason for this must be sought in the low valorisation of thermal energy;

- There are important effects on local pollution directed to the inhabitants of the plant surrounding area, and these effects can be limited only with by using co-generation (scenarios $3 a$ and $3 b$ );

- In view of the decreasing NPV with the increasing of the district heating exploitation, there are positive externalities emerging especially in the case of optimization of cogeneration (CHP scenarios 3a and 3b);

- In each case, discounted values by completely different origin cannot be added monetary values but it is worth considering that, environmentally speaking, the CHP provides more sustainable findings, although with NPV resulting from the economic-financial balance, these are less advantageous;

- The final operation scheme of energy recovery will be determined by the authority for the regulation of the public local services. 


\section{References}

[1] Arena U., Process and technological aspects of municipal solid waste gasification. A review, Waste Management, 32 (2012), pp. 625-639.

[2] Arena U., Zaccariello L., Mastellone M.L., Fluidized bed gasification of waste-derived fuels, Waste Management, 30(2010), 1212-1219.

[3] Belgiorno V., Energy from gasification of solid wastes, Waste Management, 23, 2003, pp. 1-15.

[4] Berghoff R., Kim J.G., Thermal treatment methods forwaste recycling in Germany. International Symposium Resource Recycling R and D Center / Chemistry Engineering Association in Korea, 2006.

[5] Grosso M., Motta A., Rigamonti L., Efficiency of energy recovery from waste incineration in the light of the new waste frame work directive, Waste Management, 30 (2010), 1238-1243.

[6] Panepinto D., Genon G., 2012 a. Biomass thermal treatment: energy recovery, environmental compatibility and determination of external costs. Waste and Biomass Valorization, 3:197-206.

[7] Panepinto D., Genon G., 2012 b. Carbon dioxide balance and cost analysis for different solid waste management scenarios. Waste and Biomass Valorization, 3: 249-257.

[8] D. Lgs. 11 maggio 2005 n. 133, GU n. 163 del 15/7/2005, Suppl. Ordinario n. 122, "Attuazione della direttiva 2000/76/CE in materia di incenerimento dei rifiuti.

[9] Provincia di Torino, Piano di sviluppo del teleriscaldamento nell'area di Torino, Rapporto finale, February 2009. http://www.provincia.torino. gov.it/ambiente/energia/progetti/piano_sviluppo_TLR. Accessed 02 April 2013.

[10] Fracastoro G.V, Barbero A.M., Baccon F., Politecnico di Torino: Requisiti tecnici per impianti a cippato superiori a $350 \mathrm{~kW}$. http://www.fire-italia.it /forum/pellet/all_oltre_350.pdf. Accessed 15 July 2009. 